\title{
The Investigation and Correction of the Mainstream Macroeconomics Theory in China's Economic Practice
} Thinking Based on "China Miracle"

\author{
Jing Cang ${ }^{1, *}$ Fang Liu $^{2}$
}

\author{
${ }^{1}$ School of Economics, Shandong Technology and Business University, Yantai, Shandong 264005, China \\ ${ }^{2}$ Audit Office, Shandong Technology and Business University, Yantai, Shandong 264005, China \\ *Corresponding author. Email:2993933693@qq.com
}

\begin{abstract}
Revealing the causes and mechanism of economic growth has always been a hot and core issue concerned and studied by economists and governments all over the world. To analyze the causes of "miracle of economic growth" in China's 40 years of reform and opening up has gone beyond the scope of the determinism of production factors of economic growth in mainstream macroeconomics. Based on the analysis of the representative views on "China's economic miracle", this paper studies the influencing factors of economic growth from multi-level, multi perspective and multi dimension. It holds that in mainstream economics, capital, labor, natural resources and technology are only the direct causes of a country' economic growth. However, the system and its changes, culture and national characteristics, government and its intentionality, which have been ignored by mainstream economics, are the internal reasons or basic support that determines the sustained economic growth and social prosperity of a country.
\end{abstract}

Keywords: China, Economic growth miracle, Mainstream macroeconomics, Investigation and correction.

\section{INTRODUCTION}

The mainstream theory of modern western macroeconomics originated from John Maynard Keynes' masterpiece "employment, interest rate and currency" in 1936. By the 1980s, a relatively complete system of macroeconomics has been basically established, including basic research content such as national income determination theory, inflation and unemployment theory, economic growth and business cycle theory, and macroeconomic policies. The basic framework and different research perspectives of the trinity of macroeconomic principles, macroeconomic models and macroeconomic policies has been formed. However, it should be clearly recognized that western macroeconomics came into being and developed against the background of the economic conditions and economic problems of Western Europe, the United States and other developed countries. Although it has many universally applicable general principles and methods, it is not a universal theory. Therefore, when using the theory of macroeconomics to interpret the economic reality, macroeconomic policies and economic problems of developing countries, especially the economic practice of China, it can not simply apply the basic principles of macroeconomics without analysis and regardless of China's national conditions. As a big socialist market economy country with a population of 1.4 billion and the second largest GDP in the world, China's economic development has attracted worldwide attention. And China has accumulated rich literature in economic theory, economic practice and development experience as well as macroeconomic policies, which can contribute vast and valuable materials to the theoretical innovation and development, experience summary and policy analysis of macroeconomics. Taking the miracle of 
economic growth in China's 40 years of reform and opening up as an example, this paper discusses the shortcomings of the mainstream macroeconomic theory, and tries to revise and improve it.

\section{ECONOMIC GROWTH THEORY IN MODERN MAINSTREAM MACROECONOMICS}

Economic growth is one of the main research contents of macroeconomics, and it is also one of the most widely concerned topics of governments, economists, sociologists, and the public. With the increasing population, the survival and development of mankind and the progress and civilization of society require continuous increase in material products. As far as a country is concerned, especially in developing countries, sustained and stable economic growth can provide better well-being for the residents of that country.

Generally speaking, economic growth refers to the increase in goods and services produced by an economy. According to the definition of S. Kuznets, an U.S. economist, economic growth should include three aspects: economic growth is concentrated in the growth of economic output, that is, the increase in GDP; Technological progress is a

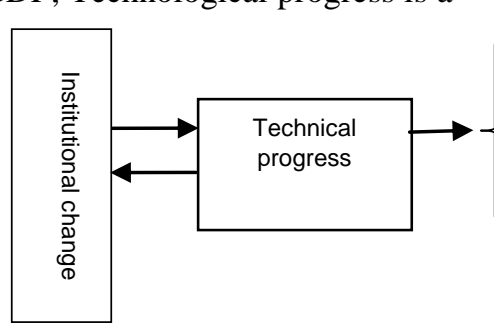

Figure 1 Factors of economic growth.

Among economic growth theories and models in mainstream macroeconomics, the three major elements of physical capital, labor and natural resources as independent variables are only the most basic production factors for economic growth. And technological innovation and technological progress are the key factors that can improve the efficiency of basic production factors, which can be the coefficient of the production function. That is to say, technological progress and technological innovation can greatly increase output and bring economic growth without increasing the number of basic elements. The system and its changes are exogenous variables that activate the vitality of basic production factors and promote technological innovation. If the time is extended, it may play a decisive role in economic growth. At the same time, necessary condition to realize economic growth. Technological innovation and technological progress can improve the efficiency of the use of human resources and material resources. And then, economic growth occurs; the sufficient condition for sustained and stable economic growth is the corresponding adjustment of system and ideology, and the adjustment and reform of social structure and ideology can promote sustained economic growth. Modern mainstream macroeconomics believes that in addition to systems, there are four main sources of economic growth: human capital, natural resources, capital, and technology, as shown in "Figure 1". It can also be described by the aggregate production function: $\mathrm{Y}=\mathrm{AF}(\mathrm{L}, \mathrm{K}, \mathrm{R})$, in which $\mathrm{Y}$ represents total output, A represents technology, L represents labor, K represents capital, $\mathrm{R}$ represents natural resources, and system is an exogenous variable. It can be seen from the aggregate production function that the source of economic growth is the accumulation of capital, the improvement of natural resources and natural conditions, the improvement of labor quality, or the accumulation of human capital and technological progress.

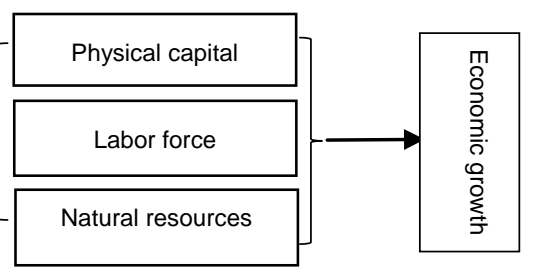

technological progress will also force system innovation and system reform, which promote and restrict each other.

\section{THE CURRENT INTERPRETATION OF "CHINA MIRACLE"}

From the reform and opening up in 1978 to 2018, China's economy has experienced an average annual GDP growth of $9.5 \%$ for 40 consecutive years. This is called the "China Miracle". So far, various books and related documents have been used to explain the "China Miracle", but most of them mainly interpret China's economic growth by the same economic miracle logic of the rapid economic development of Japan and the Four Asian 
Tigers after World War II, such as high savings, investment, export orientation, etc. which have not touched on the underlying reasons for the creation of the "China Miracle." After 2010, a batch of research results that conducted in-depth exploration of China's economic growth at multiple levels and perspectives have emerged, many of which are insightful. This article selects the masterpiece "China's Economy: Medium and Long-term Development and Transformation" written by Michael Spence and others, the Nobel Prize winner, and the views of Chinese economist Liu He, the Vice Premier. Of course, the understanding and interpretation of the economic phenomenon of "China Miracle" is far from limiting to the following viewpoints.

- The summary of the "China miracle" in "China's Economy: Medium and Longterm Development and Transformation" can be summarized in five aspects [1][2]: 1) making full use of the world economy; 2) maintaining macroeconomic stability; 3) maintaining a high savings rate and high investment rate; 4) allocating resources through the market system; 5) having a responsible, credible and capable government.

- The six factors of "China Miracle" summarized by Liu $\mathrm{He}$, a well-known economist in China and the current Vice Premier of the State Council, are as the followings [1]: 1) reflecting on the development consensus formed on the basis of the lessons of the cultural revolution; 2) unswervingly opening to the outside world, and joining the division of labor in the financial industry and the market system; 3) adhering to the marketoriented reform direction; 4) maintaining political stability and taking full advantages of the socialism system; 5) making full use of the various comparative advantages of the country; 6) and increasing supporting role played by the rich cultural deposits.

- The similarities and differences between the two explanations and traditional economic growth theories: In Spencer's explanation, the first four items are basically consistent with the abovementioned growth factors of mainstream economics, but item 5 of "having a responsible, credible and capable government" is obviously very different from modern mainstream macroeconomics, which is impossible to appear in mainstream economics' modeling of growth theory. According to Liu He's explanation, item 2 and item 3 are the elements of economic growth in mainstream economics, but the other 4 items explain their importance to economic growth in terms of ideology, politics, society, government and culture.

Some scholars believe that both Spencer's and Liu He's summary of the "China Miracle" come from experience rather than theory. These are not new knowledge concepts and ideological systems, but based on the analytical framework of the predecessors, studying the specific cause of China Miracle. Although not all of the factors they summarized appear in the aggregate production function and a mature theory has not yet been formed, it is undeniable that these factors are indeed indispensable and important variables for China's rapid economic growth. It is an irrefutable fact. In the book "China's Economy: Medium and Long-Term Development and Transformation", it is clearly pointed out that there are "striking similarities" between the experience of the "China Miracle" and that of several other countries across Asia, Africa and Latin America that maintained annual GDP growth of $7 \%$ or more for a quarter of a century or more after World War II. These factors have brought China 40 years of rapid economic growth, and it is a valuable experience for other developing countries to refer to.

In addition to the above viewpoints, Lin Yifu, one of the world famous economist, in his books of "Demystifying the Chinese Economy" and "New Structural Economics"[3][4], based on the personal experience of China's economic development and the facts of extraordinary economic achievements since China's reform and opening up, uses the analytical framework of modern economics to explain the reasons which are also different from mainstream western economic growth theories for economic growth of backward countries. Among them, "New Structural Economics" has been used by the World Bank as a model of economic development theory based on the national conditions of backward countries to guide the economic practice of developing countries, and very good results has been achieved. It can be seen that more and more scholars in China and foreign countries are gradually perfecting and surpassing the analytical framework of mainstream economic growth theory when explaining economic growth as an economic phenomenon, and applying it to the economic practice of developing countries. 


\section{THE CORRECTION TO THE ECONOMIC GROWTH THEORY OF MAINSTREAM MACROECONOMICS}

As far as the interpretation of the "China Miracle" is concerned, different people have different opinions. There are theoretical explorations, experience summaries, and cultural and policy analysis. Various schools of thought have their own opinions. If the theory of mainstream economics is used to explain economic growth, factors such as government, culture, and national characteristics are not included, but this is considered as the most essential reason in China's economic development. In this case, it is necessary to sort out or revise the existing economic growth theory based on the facts to clarify people's understanding of the existing economic growth system or to resolve the biases of the theory. After all, practice is the standard for testing theories, and theories are also used to explain or guide economic practice.

Theoretically speaking, economic growth is a long-term and even ultra-long-term macroeconomic problem, that is, the time span is at least ten years or decades, or even hundreds of years [5]. The output function $\mathrm{Y}=\mathrm{AF}(\mathrm{L}, \mathrm{K}, \mathrm{R})$ in the modern mainstream economic growth theory takes the system as an exogenous variable. Strictly speaking, it cannot be regarded as a long-term economic growth model. It only defines the endogenous causality between total output and production factors from the perspective of production factors. With the extension of the research time, many exogenous variables play a more important and decisive role, and they should be internalized. Combining with Spencer, $\mathrm{Liu} \mathrm{He}$ and other domestic and foreign economists' interpretations of the "China Miracle", as well as the latest developments in the current theoretical research on economic growth [6][7][8][9], the supplements and correction to the theory and model of traditional economic growth are as follows, as shown in "Figure 2". Among them, production factors such as capital and labor are the direct causes of economic growth, while culture, government, and social and economic systems and their changes are the internal causes (or basic causes) of economic growth, and they are production factors (direct causes) to play a role or preconditions or basic support for efficiency, similar to the function of "infrastructure". In other words, in the long run, all factors that determine economic growth should be endogenous variables of an economy's total output function.

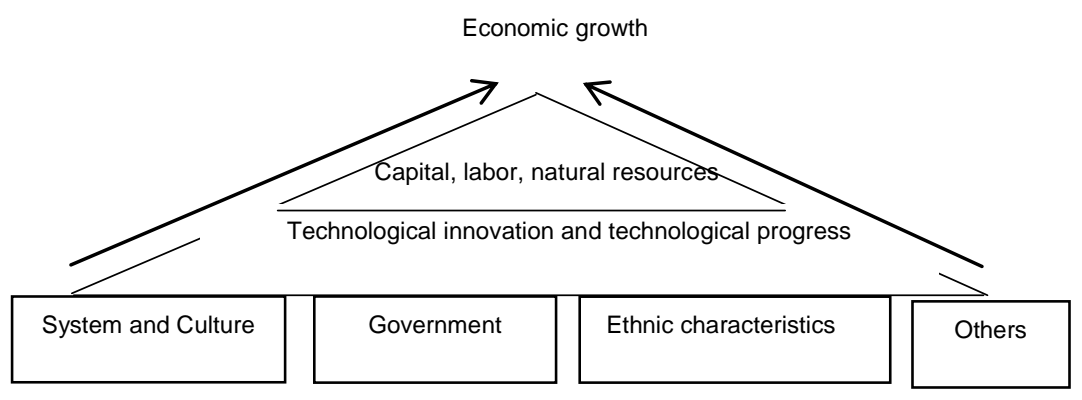

Figure 2 Comprehensive factors driving economic growth.

There is no doubt that the long-term economic growth and social prosperity of a country is a complex economic and social phenomenon. The traditional determinism of production factors in mainstream macroeconomics is obviously too simple and one-sided, and it is difficult to be justified. Internal factors such as system, culture, government, national characteristics, geography, trade, and historical development opportunities should also be included, and they all play a comprehensive supporting role. The discussion is as the follows.

At present, most economists believe that institutional factors are one of the most important determinants of economic growth. North pointed out in his famous book "Systems, System Changes, and Economic Performance": "Systems constitute incentives for people to exchange in the political, social, and economic fields. Institutional changes determine the way of social evolution and economic growth in history..."[10] It can be seen that from the perspective of long-term economic growth, the system and its changes should be the endogenous variables that explain economic growth, not the exogenous variables considered by mainstream economics. The sustained rapid growth of China's economy has benefited from the deepening of economic system reforms, opening to 
the outside world, and the continuous improvement of economic and social systems. In other words, China's economic and social systems and their changes have greatly activated and released the vitality and potential of basic production factors. And the efficiency of basic production factors has been greatly improved. Then, rapid economic growth has been achieved. This has reached a consensus in the research literature.

In recent years, mainstream economists have increasingly realized that if they want to analyze long-term economic growth and development in depth, culture and its changes are key elements that cannot be ignored. Culture, in short, refers to the shared fruits of human groups or society, such as people's values, knowledge, customs, national spirit, attitudes to life, and beliefs. Culture directly affects the development of technology and changes people's views on the natural world. At the same time, it also indirectly affects the development of technology, creating a system that can stimulate and support the accumulation of "useful knowledge" and cultivate a corresponding diffusion system [5]. Fortunately, more and more economists are devoting themselves to studying the importance of culture in modern economic growth. They believe that culture and economic growth are highly correlated because culture affects many economicrelated decisions, including the degree of hard work, willingness to save, the education level of children, and the degree of cooperation between people at work. If the cultures of different countries have different influences on these decisions, this cultural difference will naturally affect the effects of economic growth. Moreover, cultural changes will also produce a multiplier effect of economic growth, which will magnify the role of other factors of production that affect the growth of the national economy. At present, the Chinese government's cultural self-confidence, cultural power, and vigorous development of cultural industries are indeed wise, and they are also a practice and policy response to the latest economic growth theories.

The importance of government attracts more and more attention to economic growth, as the representative viewpoint mentioned above. The proper role of government in promoting economic growth is one of the oldest issues in economics. Government behavior can promote economic growth in at least four aspects: maintaining the legal system and providing public goods, the intentionality of the government, the formulation and implementation of plans [9], and the promotion of national cultural modernization and secularization to adapt and promote economic development. First of all, in essence, a market economy is an economy with a sound legal system. The government establishes a sound market economy legal system, maintains an orderly competitive market order, and creates a good business environment, which is conducive to promoting domestic and foreign investment, activating market vitality, and thereby stimulating economic growth. In 2019, China's business environment has jumped to the 31st in the world, with significant progress. At the same time, the government will naturally promote economic growth by providing infrastructure and other public goods. Especially in China, the contribution of infrastructure construction, production and scale to economic growth is indispensable. Second, the intentionality of government decision-makers is crucial in the path of economic development and the prosperity and decline of society. Since the reform and opening up, the Chinese government's economic development goals have transitioned from meeting the people's growing material and cultural needs to meeting the people's growing needs for a better life and the strategic intent of the balanced development of regions and urban and rural areas. Since then, the construction of socialism with Chinese characteristics has entered a new era. Economic growth must take into account both speed and quality, but also pay more attention to regional balance, fairness and justice. Thirdly, the formulation and implementation of China's fiveyear plan and even the medium and long-term development plan, the vision of two hundred-year goals, and so on, undoubtedly played a strong leading role and development direction in promoting economic growth and social development, macroscopically controling the potential for economic growth. Finally, the government can change the culture. The government changes culture by formulating policies, either takes it as a means to achieve certain noneconomic goals, or to create an environment that is more conducive to economic growth. Such examples can be seen in China everywhere. For example, China's effective movement of "eliminating illiteracy", promotion of Mandarin, the construction of core values of socialism with Chinese characteristics, the introduction of excellent traditional culture in campus, the promotion of family style and family education and other policies and activities have undoubtedly played an important role in improving the quality of workers, reducing transaction costs, building a good social management environment, condensing 
the spirit of the Chinese nation, and carrying forward fine traditions, which also promotes economic growth invisibly.

In addition to the production factors, institutional factors, the Chinese business spirit (ie. entrepreneurial spirit) [8] and the national characteristics of bearing hardships and living and working in peace also play an important role that cannot be ignored. Of course, if culture includes entrepreneurial spirit and national characteristics, it is not necessary to be list. However, their importance in economic growth must not be ignored. This is also a factor that cannot appear in mainstream macroeconomic growth theories and models.

What needs to be added is that Nobel Prize winners in economics, Schiller, etc. believe that: confidence, fairness, corruption, currency illusions and stories are the real motives of people's actions, and they are omnipresent, but mainstream macroeconomics believes that they have no effect [11].

In summary, for the rapid growth of the Chinese economy in the past 40 years, a direct explanation is given by the mainstream macroeconomic growth theory in terms of production factors such as abundant low-cost labor, high capital accumulation formed by high investment, high exports, and technological progress brought about by reform and opening up. The macro factors, such as the basic system of China's socialist market economy, the entrepreneur's spirit of benefiting mankind, the cultural and national characteristics of the people living and working in peace and hard work, and the basic intention of the government to govern for the people and the ability of macro-control, the confidence of the people and the government's determination and effectiveness of anti-corruption, are the internal reasons or fundamental support that determine the sustained and stable growth of China's economy, which are persistent and decisive.

\section{CONCLUSION}

With the rise of China, China has provided the world with many Chinese solutions and Chinese wisdom in economic, political, institutional, and cultural construction. Interpreting China's economic growth and development truthfully has also become one of the most important tasks for the economics community to explain economic phenomena. China Miracle not only provides the soil for the sublimation of economic theories in the $21 \mathrm{st}$ century, but also gives China's economic circles unique resources and opportunities for theoretical innovation. It can be said that economists still have a long way to go in understanding and explaining the internal mechanisms and laws of economic growth and economic operation. They should explore and reveal the internal causes of economic growth and social prosperity from various research perspectives to avoid falling into the linear thinking logic of growth theory modeling, structure and mathematics of western macroeconomics. On December 24, 2020, the National Textbook Committee of the Ministry of Education pointed out [12] that it is necessary to continuously absorb the essence of Chinese excellent traditional economic thoughts and the useful results of modern western economics, break through the compilation form of "using original theories to explain China's economic problems", build a group of new concepts, new categories, and new expressions that can systematically summarize the rich practice of China's economic construction and development over the past 40 years of reform and opening up, which should have originality, explanatory power, and identification. And then, a theoretical system of economics in China will be formed, such as "China Macroeconomics". This is the mission and responsibility of China's economic circles, and it is also an opportunity for China's economic theoretical innovation.

\section{AUTHORS' CONTRIBUTIONS}

Jing Cang is responsible for the structural design and wrote the manuscript, Fang Liu contributed to collecting materials, revising and editing.

\section{REFERENCES}

[1] Xia Bin. "China's Miracle: Reflections on Theoretic Innovations by an Economist, Economic Perspectives", 2019. 3.19. (in Chinese)

[2] Michael Spencer. "The Medium and Longterm Development and Transformation of China's Economy: Thoughts and Suggestions from an International Perspective" [M], translated by $\mathrm{Yu}$ Jiang et al., Intellectual Property Publishing Co., Ltd., 2020.1. (in Chinese)

[3] Lin Yifu. "Demystifying the Chinese Economy" (Third Edition) [M], Peking University Press, 2018.9. (in Chinese) 
[4] Lin Yifu. "New structural economics" [M], Peking University Press, 2018.11. (in Chinese)

[5] [US] Olivier Blanchard. "Macroeconomics" [Fifth Edition] $[\mathrm{M}]$ (English edition), Tsinghua University Press, 2013.4

[6] Writing Group. "Western Economics" (Second Edition) Volume 2 [M]. Higher Education Press, 2019.9. (in Chinese)

[7] [US] Joel Mokyr. "A Culture of Growth:the Origins of the Modern Economy" [M], translated by $\mathrm{Hu}$ Sijie. Beijing: Renmin University of China Press, 2020.1. (in Chinese)

[8] Wei Sen. "The Real Logic of China's Economic Growth" [M]. CITIC Publishing House, 2017.7. (in Chinese)

[9] [US] David N. Well. "Economic Growth" [M], translated by Jin Zhinong and others. Beijing: Renmin University of China Press, 2007.11. (in Chinese)

[10] [US] Douglas C. North. "Institutions, institutional change and economic performance" [M], translated by Hang Xing. Shanghai: Gezhi Publishing House, 2017.1. (in Chinese)

[11] [US] George A. Akerlof, Robert J. Shiller. "Animal Spirits" [M], translated by Huang Zhiqiang and others. Beijing: CITIC Press, 2012.12. (in Chinese)

[12] Office of the National Textbook Committee of the Ministry of Education. "Notice on Carrying out the Application for the First Batch of Chinese Economics Textbooks". Official website of the Ministry of Education, January 5, 2021. (in Chinese) 